\title{
Queerious Youth: An empirical study of a queer youth cultural festival and its participants
}

\begin{abstract}
Various institutional legacies and contemporary social circumstances often work to constrain the voices and cultural expressions of gender and sexually diverse young people. However, gender and sexually diverse youth can also respond critically and creatively, generating their own sites of cultural participation and meaning. Through an empirical case study of Queeriosity-a queer youth cultural festival held in Brisbane, Australia - this article details the impetus behind the creation of this youth-led event. Secondly, drawing on participant observations and survey data collected at the festival, this paper provides a 'snapshot' of the various identities, attitudes and cultural styles that circulate within Brisbane's queer youth communities. Finally, it argues that the spectacle, celebration and diverse articulations of youth sexualities which underpinned Queeriosity provided participants with opportunities for sexual self-making.
\end{abstract}

Key words: queer; youth; culture; identity; festival.

\section{Introduction}

Since the medicalisation of homosexuality in the late $19^{\text {th }}$ century, same-sex attracted people have been subjected to cruel and unusual psychological and physiological punishment (Foucault 1979). Prevalent throughout the larger part of the $20^{\text {th }}$ century, attempts to 'cure' homosexuality included aversion therapy, shock treatment, lobotomies, hypnosis, drug therapy, castration and hysterectomies. The American Psychiatric Association decided to officially remove homosexuality from the Diagnostic and Statistical Manual for Mental Disorders in 1973. In the late 1960s and early 1970s the countercultural politics of gay liberation set about redefining the mainstream view of gay and lesbian people, materialising queer counterpublics, advocating a new sense of identity based on pride and ultimately seeking to liberate all people's repressed erotic drives (Altman 1972). Currently, under a neoliberal guise of tolerance and inclusion, 'one that is driven to mainstream or normalize gay and lesbian people as a strategy of gaining entry into civil society' (Talburt et al. 2004: 2), empowerment often comes at the price of santatising one's self-image in order to 'fit in' and feel 'normal' (Martino and Pallotta-Chiarollli 2005). For young people, this message of acceptance through compliance can stifle diverse presentations of sexual selves. This is particularly so for young people negotiating multiple partial subjectivities that fall between the gaps of the implicitly white hetero/homo divide (Pallotta-Chiarollli 2011). 'What is especially disturbing' argues Driver, 'is the almost complete silence surrounding queer youth sexual pleasures, subcultural counter publics, and political resistance. Normalization works to desexualize and depoliticize youth once again, creating safe, sanitized images that conform with white middle-class standards of visibility and value' (2008: 5). Too often, it is these negative, limited or normalised impressions that pervade dominant narratives of queer life, leaving very little room for alternative accounts of positive selfhood, vibrant and complex communities, rich cultural practices, and youth-centred accounts of queer cultural styles that signal visible identities in specifically queer terms.

During the period November 2009 to April 2010, I took part in organising a queer youth cultural festival called 'Queeriosity' in Brisbane, Australia. The ultimate goal of this event was to facilitate a space where queer youth could feel at ease to make and participate in local queer culture and (re)make sense of their own identities and community. In comparison to the larger Australian capitals of Sydney and Melbourne, Brisbane (although the third-largest city in Australia) has significantly fewer venues and events that cater to gender and/or sexually diverse people, especially under-age youth. While Sydney youth organisation Twenty-10 offers the Gay and Lesbian Mardi Gras youth festival and Melbourne organisation Minus 18 frequently runs youth dance parties, 
workshops and youth activities during the Midsummer Festival, Brisbane has not previously offered any comparable large scale events that cater specifically for queer youth. Historically, Brisbane (the state capital of Queensland) has been less accommodating to sexual difference than Sydney or Melbourne. Queensland was one of the last states to enact homosexual law reform, finally decriminalising homosexual activity in 1990, and continues to uphold inequitable age of consent laws which currently stand at 18 years for anal sex while vaginal and oral sex is permissible at age 16. Moreover, in a 2010 survey conducted by Roy Morgan Research, 13.6\% of the Brisbane residents surveyed reported that they believe homosexuality is immoral. This percentage drastically increases in Brisbane's surrounding regions making Queensland the most homophobic state in the country according this survey (Trenwith 2010).

In this article, I focus on Brisbane's 2010 Queeriosity festival and its community of participants. Firstly, using empirical data drawn from participant observation, group discussions and surveys, this article examines the multiple forms of identification, cultural styles and attitudes of queer youth in a local context. Contextualising this data within existing literatures on queer youth as I have done here, provides a localised and always partial, but recent 'snapshot' of the various circumstances, attitudes and identities that circulate within Brisbane's queer youth communities. Secondly, this article also argues that the spectacle, celebration and diverse articulations of youth sexualities which underpinned Queeriosity created new opportunities for sexual self-making, encouraging the exploration of multiple forms of queerness, promoting connection and understanding across multiple queer communities and exposing young people to the many ways of identifying and presenting oneself.

The term 'queer youth' is used in this article to broadly signal young people whose sexual and/or gendered identities, practices, performances, and/or desires transcend the limitations of 'straight' gender and/or sexual categories. I employ the notion of 'queer youth' as an invocation of the messy processes of identity, embodiment, desire and as a form of resistance to pathological and taxonomical discourses: 'a site of analysis and critical questioning that works against binding young people within new definitional regimes of control' (Driver 2008: 2). Queer youth offers a framework of cultural intelligibility that is resistant to the inscription and naturalisation of the homosexual/heterosexual binary (Talburt et al. 2004). While I acknowledge that this term 'queer' may not be directly employed by all the young people who participated in this study, I choose to use the term as a multivalent signifier that can encompass a range of sexual and gender non-conforming identities and practices. Later in this article I do provide some disaggregation regarding the identificatory terms employed by the young people in this study, therefore, the term 'queer youth' is of principle value here as means of framing young people rather than as a delimited identity signifier.

\section{Festival description and research methods}

Queeriosity was a free, one-day cultural festival staged on 18 April 2010 during National Youth Week. The festival's target audiences was lesbian, gay, bisexual, transgender, intersex, queer, questioning and curious young people aged 25 and under. The event was run through Open Doors, a Brisbane-based support service for young people who identify as lesbian, gay, bisexual, transgender, intersex and/or queer (LGBTIQ) or who are exploring or questioning their sexuality and/or gender identity. A central goal of Queeriosity was to provide queer youth with an opportunity to demonstrate their own creative practices and/or be involved in all aspects of the festival planning, programming and stylistic decision-making so as to generate a strong sense of youth community ownership and direction. To this end, a team was established that comprised myself, two adult youth/LGBTIQ social workers, a young social work student from Open Doors, and most importantly, a steering committee of young people aged between 14 and 22 who access Open Doors youth services and volunteered their involvement in planning the event. ${ }^{\mathrm{i}}$ As I was involved in the strategic development of the festival, I was privileged to spend a considerable amount of time with these young people throughout these decision-making processes. 
Queeriosity was underpinned by multiple ideological strategies and goals determined collectively by the youth-led steering committee. These included: providing a fun and engaging drug, alcohol and discrimination-free social space for queer youth; acknowledging the diversity of queer youth desire, creativity and lifestyle choices; creating a space in which queer youth could feel safe and at ease to present themselves in a manner of their choosing; a space to socialise and make new friends; facilitating opportunities for young people to engage with LGBTIQ and youth specific literatures, politics, organisations and services; facilitating connections between young people and the broader LGBTIQ communities through cultural participation; and to give young people the chance to see diverse representations of queerness and multiple modes of self-presentation.

As a steering committee the young people were responsible for naming the festival; designing the event poster; decorating the festival space; five young people volunteered themselves to perform at the event; two young people nominated to speak publicly in a gender and sexuality discussion forum which was run during the event; while others participated in event publicity through radio interviews. Stalls at the event provided information on a range of topics that the steering committee decided would be of interest to themselves, their peers and their community, including advice on sexual health; mental health; queer legal rights and law reform; general human rights issues; environmental politics and eco-living; queer-friendly church groups; and queer-specific social services and support groups for young people and their families/carers. Where possible, supplies and infrastructure - food, sound reinforcement, stage management, advertising and distributionwere sourced from queer owned or operated businesses that were made visible to young people through the event. Performers, workshop facilitators and cultural activates were chosen by the youth steering committee to represent queer gender, sexual, ethnic, racial, political, stylistic and creative diversity as much as possible. Table 1 below lists and briefly describes the variety of performances and interactive workshops that the young people selected as part of the festival program.

Table 1. Queeriosity performances and workshops

\begin{tabular}{|c|c|}
\hline Live performances & Workshops and interactive activities \\
\hline $\begin{array}{l}\text { Aunty Dawn: Welcome to Country } \\
\text { Lesbian Aboriginal Elder who welcomed everyone to her } \\
\text { country. Also a musician, Dawn sang and played } \\
\text { acoustic guitar. }\end{array}$ & $\begin{array}{l}\text { Skateboarding classes facilitated by a member of the } \\
\text { transgender community. }\end{array}$ \\
\hline $\begin{array}{l}\text { Robin Wittika } \\
\text { Transgender comedian }\end{array}$ & $\begin{array}{l}\text { Stencil art/graffiti workshop. Facilitated by local lesbian } \\
\text { street artist. }\end{array}$ \\
\hline $\begin{array}{l}\text { Queer Youth Performance Showcase } \\
\text { A range of performers all under } 25 \text { displayed their } \\
\text { talents. Acts included a Lady Ga Ga parody drag queen, } \\
\text { contemporary dance and burlesque-style cabaret. }\end{array}$ & $\begin{array}{l}\text { Gender and sexuality discussion forum where both } \\
\text { young and older members of the community discussed } \\
\text { identifying as queer, lesbian, gay, bisexual, genderqueer, } \\
\text { transgender (male-to-female and female-to-male). }\end{array}$ \\
\hline $\begin{array}{l}\text { Ofa Fanaika } \\
\text { Queer Polynesian soul-singer and songwriter. }\end{array}$ & $\begin{array}{l}\text { Beading workshop run by a queer youth workers from } \\
\text { Open Doors. }\end{array}$ \\
\hline $\begin{array}{l}\text { Evelyn Hartog } \\
\text { Performance art/spoken-word/drag king }\end{array}$ & $\begin{array}{l}\text { Badge-making workshop run by a local university queer } \\
\text { student-group. }\end{array}$ \\
\hline $\begin{array}{l}\text { Anarchist Duck } \\
\text { Funk/reggae/rock band }\end{array}$ & $\begin{array}{l}\text { Zine-making workshop run by a regional queer youth } \\
\text { support group. }\end{array}$ \\
\hline $\begin{array}{l}\text { Abrile Latrene } \\
\text { Prominent local drag queen }\end{array}$ & $\begin{array}{l}\text { Stress ball-making workshop run by a queer youth } \\
\text { support group from a neighbouring city. }\end{array}$ \\
\hline $\begin{array}{l}\text { Edge of Colour } \\
\text { Electro avant-pop band }\end{array}$ & Circus workshop run by queer circus performers. \\
\hline $\begin{array}{l}\text { DJ Ish } \\
\text { Prominent house music deejay on the local gay nightclub } \\
\text { scene. }\end{array}$ & $\begin{array}{l}\text { Queer screening room, which showed a queer youth- } \\
\text { themed film, But I'm a Cheerleader (1999). }\end{array}$ \\
\hline
\end{tabular}

Using a largely qualitative multiple-method approach, I collected empirical data from young people over the course of the festival development. This included participant observation and taking field notes during 10 festival planning meetings with young people and youth workers, each approximately two hours long; talking to young people who attended Queeriosity; and facilitating a focus group with 15 willing young people and four youth workers three weeks after the event. All 
of the young people I talked to and surveyed were made aware of my role as a researcher. Given that the age of people who access Open Doors ranges from 12 to 24 and that the festival was staged to appeal to a 25 and under age group, appropriate ethical clearance was sought from the Office for Research at my university allowing me to observe, talk with and survey minors. In the case of formal group meetings and discussions, participants all gave informed consent.

On the day of Queeriosity, 60 paper-based surveys were deployed using a convenience sampling method. All surveys were completed anonymously and attached to the front of each survey was a guideline to informed consent. As best as possible, this sample attempted to be representative of the attendant demographic, however as literature on sampling methods suggest, a sample of any population can rarely be representative of the whole (Robson 2000). Festival entrypoint monitors recorded attendance of the event by 231 young people, thus $25 \%$ of the audience completed surveys. The surveys consisted of 22 questions that were a mixture of multiple-choice and open written response. Where required answers were short or multiple-choice, completion rate was almost $100 \%$, however, on the nine occasions where respondents were specifically asked to extrapolate on their answer, approximately only half of all respondents did. One could speculate that respondents simply did not want to take the time to give longer answers given the entertainment and activities on offer. While the effect this had on the broad applicability of my data cannot be precisely measured, I would argue that it was minor as the responses given clearly indicated trends in opinion.

The survey questions were aimed to gather a range of information about queer young people including: basic socio-economic and cultural indicators; modalities of identification; stylistic persuasions; types of cultural participation; and their attitudes, cultural values and anxieties. Once all data collection processes were complete, individual data sets were coded and analysed for emerging themes and then all data sets were synthesised to create this 'storied reality' (Madden 2010). Where possible, I have attempted to demonstrate the broader applicability of my data by contextualised my findings within existing studies. But, in the absence of comparative data on other locals and because the design of the festival was such that it responded specifically to the young people's needs and wants in a local context, this study has limitations and the findings cannot be considered indicative of queer youth identifications, attitudes and experiences outside this urban setting. However, the value of this study is not diminished as it provides important data of significant depth on youth sexualities and culture in Brisbane, which has currency for those working with queer youth and in associated support services, and has potential practical and policy implications. Furthermore, the detailed account of the festival design is valuable to those interested in festival studies and community cultural development.

Undoubtedly, my duel roles as both an assistant to the youth steering committee and a researcher impacted upon the collection, reporting and evaluation of the data and the event. During some of the planning meetings and follow-up focus group session, I believe that my presence initially affected some of the young people's willingness to speak candidly as I was an unfamiliar body in their space. Comments made to me by youth workers regarding how 'quiet', 'shy' or 'unusually lacking in opinion' some group members were, suggested that my unfamiliar presence initially had some affect on the group's openness. Not an uncommon experience as an ethnographer, this became noticeably less problematic the more time I spent with them. Upon reflection I can see that my embodied situatedness as queer and relatively young (under 30) coupled with my willingness to communicate some one my own experiences of the delights and difficulties of queer lives made the young people who served on the steering committee more willing to share their opinions and experiences with me as we grew more familiar with each other. In carrying out my evaluation of the event, I must openly declare that distancing myself from my emotional investments and my desire to continue working with these young people towards future incarnations of Queeriosity has been challenging when trying to maintain critical authority. Of course the epistemological problems surrounding multiple field roles and degrees of 'insiderness' are not unique to this project and have been extensively written about (e.g. Hodkinson 2005, Madden 2010; Author 2011). I have tried my best to uphold my ethical commitment to the research while also 
acknowledging that the culture I am constructing in my writing is also one I am now personally embedded in.

\section{Festival attendees: a local snapshot of queer youth}

Based on the survey data and confirmed through observation, the majority of festival participants were between 15 and 17 years of age. The youngest recorded participant was 13 while the oldest was 28. Approximately a third of those surveyed attended high-school, a third were currently at either university or technical/further education colleges, and a third had either full or part-time employment (many did this while also receiving education). Only seven of the 60 respondents listed themselves as unemployed. Of those surveyed, 73\% identified as Anglo-Australian, 5\% as Aboriginal, 5\% as Hispanic with the remaining participants identifying either as Italian, Greek, Lebanese, Polynesian or Asian. Data from previous American (Grov et al. 2006) and Australian (Hillier et al. 2005) studies show young people from culturally and linguistically diverse backgrounds are less likely to have come out to their families, which may explain lower level of ethnically diverse attendees. Indeed, the survey responses reflected this, as only $40 \%$ those who identified as ethnically diverse reported being out to their families/primary carers and of these, only $25 \%$ indicated that their families were accepting. Reasons for lower levels of ethnically diverse attendees may be due to prioritising the development of racial/ethnic identities or perhaps this event did not appeal to ethically diverse queer youth. While an attempt was made to represent ethnic and racial diversity through performance at Queeriosity (see Table 1), this suggests that further investigation into whiteness and race privilege (Riggs 2006) and cross-cultural engagement strategies within the local context are needed. Among the whole population surveyed, the rates of gender and/or sexual minority identity disclosure were much higher than those stated above with $68 \%$ indicating they were out to their family/primary carers and of these, $75 \%$ said their family/primary carers were accepting. Friendship groups however, appeared to offer greater support and acceptance with $83 \%$ reporting being out to friends and of these, $98 \%$ reported that their friends were accepting. The support of friends identified here was in keeping with the findings of existing Australian research that also suggests young people are more likely to come out and seek the support of their friends than their family (Hillier et al. 2005).

On the survey, respondents were also asked to identify themselves by their sex, their gender and their sexual identity. In relation to sex: $68 \%$ identified as female; $30 \%$ as male; one person identified as female-to-male; one person identified as male-to-female; and one person was unsure. The large proportion of female attendees compared to male attendees was something that in the focus group following the event, a number of the males remarked on. 'It kind of felt like a lesbian event' one of them said (field notes, 12 May 2010). Young women however disagreed, indicating they didn't perceive this at all. Admittedly, my field notes did not contain anything that suggested there was a much greater proportion of females in attendance. In relation to gender identity: 58\% identified as feminine; $25 \%$ as masculine; $13 \%$ were unspecified or unsure; with remaining responses equally distributed between femme, butch and genderqueer. In relation to sexual identity: $25 \%$ identified as lesbian; $22 \%$ as bisexual; $20 \%$ as gay; $16 \%$ as queer; $11 \%$ as straight; $6 \%$ were unsure. ${ }^{\text {ii }}$ The labels these young people apply to themselves are multiple and diverse and as the statistics suggest, there is a distinct lack of cohesion between categories of sex/gender/sexuality. In other words, the sex, gender and sexual identity labels young people assign themselves often troubles the normativities of heterosexual hegemony (Butler 1993).

Linné (2003) argues that shallow representations of queerness in cultural texts have the potential to distort the creation of self-image and self-presentation for queer youth. To explore this, the survey asked respondents to give their opinions on media representations of queerness. $68 \%$ of respondents admitted to actively seeking out queer-themed TV shows and/or movies. However, when asked if they felt their reality was reflected in on-screen LGBTIQ characters, the majority said no. In their extended responses participants demonstrated a keen ability to critique media and a reflexive understanding of queer stereotypes and the broader implications of these on perceptions of 
queerness generally: 'It's always people adhering to the gender binary and I don't play that way', one person wrote. 'Not all gay males are feminine queens ... Carson Kressley [camp fashion presenter for the television series, Queer Eye for a Straight Guy] is a classic example', wrote another. Yet another remarked: 'Either we're portrayed in a negative light (e.g. villains), victims (e.g. Boys Don't Cry, Mambo Italiano), or we're the ignored/funny unimportant character ... in Queer as Folk, we're displayed as shallow, beautiful party-goers'. Pointing to the lack of queer teen representation in mass media, age was another significant factor raised by some respondents who felt that LGBTIQ characters were always much older than them and therefore, unrelatable. Overall, these young people appear highly critical of the politics of media representations and, for the most part, they appear angered by the essentialist gender and sexual dichotomies presented in a significant amount of mass media which repeatedly reduces queerness to recognisable formulas and easily digestible images - a reductive framework that is 'heterofriendly and nonthreatening' (Shelton 2008: 75). 'These normative roles are caricatures, fragments of the better-developed characters of their heterosexual counterparts', as Shelton (2008: 74) describes them, are astutely detected by young queer media consumers: 'Oh where do I begin', one young woman responded, we are 'a novelty, a triviality', we are 'represented as heteronormative homosexuals'.

In an attempt to understand how these young people perceived their marginalised status, survey respondents were asked to comment on what they thought was the best and the worst thing about being LGBTIQ and also to give their opinion on important social issues that relate to their minority status. Connotations of free expression were the most common response to the question asking 'what is the best thing about being LGBTIQ'. Response rates to this question were very low and typical responses included: 'Freedom to be myself'; 'being myself'; and 'living the way I want to live', 'being comfortable within myself and my community'. The dominant negative themes that emerged pointed to a high level of anxiety surrounding discrimination and violence thus, suggesting that young people fear that the freedom of self-expression and presentation they value so much is threatened. The response rates to the question asking 'what is the worst thing about being LGBTIQ' were significantly higher. For younger respondents (14-16 years), responses such as this: 'discrimination, homophobia and my parents not understanding', were common. While older respondents (17-20+ years), evoked stronger language. For example, one respondent wrote: 'Alienation, ostracisation. Being fucked over by the government. Violence, stereotyping, bigotry, prejudice. Heteronormativity, homophobia, transphobia, queerphobia, gender stereotypes'. When asked to indicated what they through was the most pressing social justice issue for LGBTIQ people, the most common response was same-sex marriage rights with a notable number of people also highlighting recognition of same-sex parents and adoption. Heterosexism/homophobic bullying in schools and workplaces was the second most prominent concern. Overall, the young people surveyed were more willing and able to give detailed responses to the negative aspects of being LGBTIQ and less able to provide positive and affirming responses.

Here we see a striking example of how the tropes of oppression and victimisation that frame queerness pollute young peoples' self-perceptions and limit their potential for full and fearless social participation (Talburt et al. 2004). Upon coding the data, it also became evident that fear inhibits young people's ability to act upon their queer desires. Some people noted they were afraid of displaying their attractions or sharing their feelings in case the recipient reacted violently and others were afraid to be publically affectionate with a same-sex partner for fear of negative attention. Moreover, there is evidence to suggest that fear of seeking and displaying affection may result in the erotic disempowerment of queer youth, as there was a stark lack of reference to sexual pleasure in survey responses where one might have expected it. In response to the question that sought their opinion on what they liked most about being queer, only four out of 60 people made any reference to sexual pleasure or their desire and even those who did, did so moderately. One bisexual-identified male insinuated he liked being this way because he got to experience 'both genders'; one female respondent said 'girls, girls, girls'; similarly, a male respondent said 'guys'; and, in a manner that suggested comical provocation, another male respondent said 'bum sex'. Further evidence to suggest that these young people may feel uneasy or ill informed about queer sex can be detected in their response to an open question which asked them to state the kinds of 
LGBTIQ-specific topics they would like to know more about. Of those who responded to this question, the majority related to pleasure and desire. 'Sex in general and relationships', said one person and 'couples in gay situations', said another.

Jackson and Scott note that for young people in general, 'there is little focus on becoming sexual as a process; rather it is seen as a matter of leaping a chasm between 'innocence' and 'knowledge'' (2004: 235). For queer youth who are subjected to processes of normalisation, necessitated by 'fitting into' mainstream society, it can be even harder to become knowing sexual subjects. Since queer sex is seen as deviant, adults and institutions are less likely to make queer sexual knowledges available to young people. For example, Hillier's et al. (2005) Australian study shows that the majority of young people (93\%) reported learning about heterosexual sex in schools, with only a small proportion (27\% gay youth and $21 \%$ lesbian youth) leaning about queer sexual practices in the same setting. The focus on sexuality as dangerous and deviant 'is reinforced by the absence of overt queer sensuality in mainstream books, movies, and television' argues Linné (2003: 676, emphasis in original). Living as these young people do-with fear of persecution, with little positive reinforcement regarding queer sensuality and in a state that upholds unequal age of consent laws and is reportedly the most homophobic in the country - it is perhaps not surprising that the young people surveyed may feel erotically disempowered. Part of Queeriosity's design was to facilitate a site for sexual learning via information stalls on sexual health and relationship counselling, safe-sex discussions and instructive workshops. While analysis of these provisions is beyond the scope of this study, these preliminary indications are concerning and highlight the need for further funding and resources to do follow-on research within and beyond Brisbane's queer youth communities.

\section{The festival as a potential site of ritualised practice}

LGBTIQ festivals are now a ritualised practice of sexual minority communities and are a 'means by which the imagined gay community can be materialized in space through publicly celebrating their culture, pride, traditions, symbols, and mythologies, which for much of the time remain hidden from public view' (Waitt and Markwell 2006: 217). Pride festivals, for example, are attended by millions of people around the world each year and for many who participate, these events can provide an important opportunity to assert a sense of self while also taking part in the collective expression of LGBTIQ culture, community and resistance, resulting in stronger feelings of connectedness and empowerment (Kates and Belk 2001). ${ }^{\text {iii }}$ But, as many young people indicated during the planning stages of Queeriosity, full participation in this imagined community is almost impossible for young people. In Brisbane at least, young people have limited access to queer public spaces and limited ways to materialise queer youth communities in these spaces as the majority of distinctly LGBTIQ public spaces are bars and nightclubs, which patrons must be 18+ years old to legally enter. Similarly, Brisbane's annual gay street party, Big Gay Day and its annual Queer Film Festival also restrict entry to $18+$ years. While Brisbane's Pride Festival Fair Day is technically an all ages event, fenced areas tend to segregate younger and older social groups, as those under 18 are not allowed to enter alcohol-service areas. Clearly frustrated by the way licensing as well as censorship $^{\text {iv }}$ regulations exclude young people from or subject them to different rules within certain queer public spaces, one young woman said to me: 'It sucks being 17 ... I can't go to Gay Day with my girlfriend ... I don't even get to see my friends that much on the weekends anymore ... I can't wait until I'm 18 'cause then I can finally hang out with them again on a Friday night again'. A young man aged 16 also commented: 'Yeah, like I so want to go to the Queer Film Festival but we can't, but I look at the program and download some of the movies but it's not the same' (field notes, 15 March 2010).

Events such as Queeriosity which are uniquely created by and for Brisbane's sexually and gender diverse young people point to the age-based cleavages that shape LGBTIQ social spaces and highlight the significance of a celebratory space that is youth-focused. 'Created by and for young people' was central to all event publicity and the event's focus on specifically celebrating gender 
and sexually diverse youth rather than gender and sexual diversity tout court was the reason the event was staged in National Youth Week rather then during Brisbane's official Gay Pride month of June. Notably, Queeriosity was the only event in Australia that catered specifically for queer youth communities in National Youth Week. In this final section, I argue that the spectacle and celebration of youth sexuality which underpinned Queeriosity provided young people with the space to create and access culture and ideas that resource the reflexive social project of sexual selfmaking (Skeggs 2004).

Adolescence is a crucial time during which sexual feeling and actions are evaluated as part of the development of a sexual self-concept. Halverson writes that 'the opportunity to participate in organizations that can facilitate and support exploration of possible selves is a crucial aspect of the adolescent identity process for queer youth' (2005: 71). Similarly, Shelton writes that it is important to give queer youth 'a space in which they can join with other youth in the articulation of identities', empowering them to "create their own cultural practices and to alter the ways in which they are conceptualized by people and institutions' (2008: 69). As the snapshot of the festival attendees demonstrated, the circumstances, identities, attitudes, apprehensions and cultural styles of queer youth are multiple and diverse. Young people articulate their gender and sexual difference in tension with social norms and quite often in tension with each other. On the day of the festival, the gender and sexuality discussion forum (see Table 1) provided a space where conversations on this topic could be played out. Approximately 35 young people attended the forum to listen to five gender and sexually diverse community members share their complex 'identity journeys'. ' This sparked interesting audience dialogues in which young people expressed their varied opinions on what it means to be LGBTI and/or Q. Boldly pointing to the queer youth heterogeneity, there was much debate and disagreement in the room. One young gay-identified man shared his anger toward his mother who has recently come out as lesbian. 'I was born this way' he said, 'and I just don't understand how after all this time she just gets to choose' (field notes, 18 April 2010). While other participants shared stories and opinion that suggest they view sexuality as more flexible, the social pressures experienced by young people to choose and fix one's sexuality also emerged. For example, one young woman spoke about her bisexuality and how she has to 'pretend' to be a lesbian because her lesbian friends are bi-phobic. The range of identificatory terms young people in the audience used to describe themselves during the forum discussion suggested that some people were quite identity-literate. Those terms I managed to record in my field notes included lesbian, gay, bisexual, queer, butch, femme, queer/bisexual, queer/dyke, pansexual, genderqueer, cisgender and transgender among others. As the facilitators explained some of the more ambiguous terminologies, it was also quite obvious that many of these terms were completely new to, or angered other participants: 'you're either gay or straight and that's it', said one young man while others agreeably cheered him (fieldnotes, 18 April 2010).

Given the politics and tensions surrounding gender and sexual identification, and the pressures of conformity acknowledged by these young people, it is important that they are equipped with the necessary tools for undertaking this complex identity work. The festival space acted as a valuable site for knowledge-transfer and festival participation gave these young people valuable opportunities to express and (re)construct self-perceptions and identifications. Young people keenly took up the opportunities to publicly share their stories and to engage in critical dialogues with other young people both in the forum settings and in more informal conversations that were had around interactive badge-making and zine-making tables on the day. In the focus group that was run after the event discussions regarding identificatory terms were quickly taken back up, specifically relating to the name 'Queeriosity' and its branding as a 'queer youth cultural festival'. One young woman commented: 'I probably wouldn't have come unless it had the word queer in it as I don't generally like lesbian and gay stuff all that much' (field notes, 12 May 2010). Two others in the group agreed with her and all three were around 17-20 years of age and attended university. Following this, a young man (around 14 years) said, 'but I don't even know what it [queer] means', to which others (also around 14-15 years) agreed. 
Age and education proved to play a significant part in young people's self-concepts and broader understanding of gender and sexuality. All the people on the survey who identified as queer, pansexual or genderqueer were 17+ years old. Given the limited exposure of school-aged young people to different ways of thinking about identity, this suggests, as have previous studies (Hillier's et al. 2005) that theoretical concepts such as queer, pansexual or genderqueer are learnt in university, activist or community contexts. For many young people, particularly those who are school-aged, Queeriosity was the first time they had even engaged with these terms and concomitantly with people who, for example, present themselves as genderqueer or identify as pansexual. Moreover, in the focus group and in post-festival discussions many young people acknowledged that the festival reinforced and/or gave them the opportunity to explore different forms of self-presentation. One woman in her early 20s, who I had never met before, approached me at a social gathering some months after the festival and said, 'you're that Queeriosity chick, oh my god you have no idea how great it was to hear all your stories'. She was referring to the gender and sexuality forum. She went to say, 'I just felt so much pressure to be butch, but I love that you're like femme and queer and it was just so great to see someone else who was femme and that other people are totally fine with it and it really inspired me to just be myself' (field notes, 6 August 2010).

Also indicated by the survey data, while many young people seek out queer narratives in popular culture, they are discerning consumers and often find it difficult to relate to the dominant characterisations of queerness. During the festival planning, the youth-led steering committee who programmed the entertainment were conscious of giving festival attendees the opportunity to engage with gender, sexual, ethnic, racial, political and stylistically diverse people and culture. Both on the day of the event and in follow-up conversations many young people acknowledge that the festival introduced them to cultural narratives that expanded their perceptions of queer lifestyles and culture and/or validated their self-perceptions. When talking with a group of young women on the day, for example, they expressed to me, their pleasant surprise at discovering new queer female musicians: 'like I didn't even think we had any dyke bands in Brisbane' (field notes, 18 April 2010) said one of them. In the focus group after the event there was almost unanimous recognition that their view of what constitutes queer culture had been expanded. Also during the focus group, two young people talked to me about meeting adult workshop coordinators and stall holders at Queeriosity, suggesting that these engagements made them feel better about themselves: 'You know, clubs and Mardi Gras and stuff like Queer as Folk and sometimes even Pride kind of make it out like it's all about, um, half-naked men, drag queens and like getting wasted at parties' said one young man. His female friend then cut into the conversation and said 'yeah, Queeriosity didn't feel that kinda gay, I guess we're kinda strange anyway but the circus women were really great and I kinda talked to the guys on the eco stall too ... yeah, it was great to meet other alt [alternative] queers' (field notes, 12 May 2010).

As with youth in other identificatory contexts (e.g. Bennett 2000), self-presentations that drew on subcultural and musically mediated style as a way to engender collective belonging were particularly strong. Pointing to the pivotal role of subcultural style in the symbolic differentiation of gender and sexually marginalised youth from one another, stylistic affiliations - from subtle visual cues to extreme-were performed by cliques in the planning meetings and on the day of the event. As one transgender male said to me, 'I'm more into hardcore punk' and 'hang out mostly with other hardcore kids' (field notes, 18 Feb 2010). Another group of young men said they were all into 'the usual gay stuff'. When I asked them what they meant by that one of them replied, 'you know like Lady GaGa, Madonna, Kylie, George Michael and Adam Lambert (field notes, 18 Feb 2010). On the day of the festival too, a number of subcultural cohorts were visible. A group of queer teenage women who presented themselves as goth (or possibly emo) spent much of their time together as did young people who presented alternative/punk persuasion in their dress. Another notable friendship trio who always associated with each other in meetings and on the day, described themselves to me as 'burlesque punk' (field notes, 18 Feb 2010) and it was through frequent discussions of music and through two of them performing a cover of their favourite Dresden Dolls song at the festival that they articulated their interpretation of a queer identity and distinguished 
themselves from their peers. In addition to music-centred subcultural style, a number of young people also used Queeriosity as an opportunity to present themselves in queer subcultural fashions such as leather or drag - something that can't always be done with ease in non-queer social contexts. In focus group and follow up discussions with the steering committee, young people overwhelming expressed a deep sense of empowerment through, as one person said, 'seeing all the different ways people can be gay' (field notes, 12 May 2010). In other words, the image of a queer community that was spontaneously generated in the festival setting resisted homogeneity and containment. This dialogical process of fashioning and communicating multiple interpretations of queerness allowed young people to elaborate meanings and explore new scripts for sexual selfmaking.

\section{Concluding thoughts}

In this article, through the lens of a queer youth cultural festival, I have provided a glimpse into Brisbane's queer youth communities. While I acknowledge that this is only a partial glimpse, it gestures towards an understanding of queer youth as irreducible to bounded sexual and stylistic mappings. Queer youth frequently articulate identity in tension with both the heteronormative mainstream, homonormalising cultural representations and, at times, each other. While avid consumers of popular culture, queer youth demonstrate their ability to critically analyse images and assumptions that mis/represent them or falsely universalise queer youth narratives. They exhibit plural modalities of identification; diverse scales of self-perception; and complex, fluid and broadranging styles of distinction and self-presentation.

Although this paper has not answered questions regarding who didn't participate and why, which is a necessary area of future investigation, what I have demonstrated is that for many of those who did participate, the (re)imagined community materialised though the festival generated a social context where young people could locate themselves in relation to individual and multiple others, providing young people with a means to experience temporary forms of community predicated on the convergence of multiple queer identities and representations. This article only represents the first steps towards evaluating the impact of Queeriosity and better understanding its community of participants. In May 2011, Queeriosity Two was held and attended by 460 young people, doubling 2010's attendance. Again this year data was collected and once analysis is complete I intend to develop this work further so that we may more fully understand the impetus and benefits of participation, the obstacles that inhibit participation, the dynamics of this local queer youth community and the significance of the festival as cultural modality in this context. While there is still important work to be done, I believe that this preliminary examination suggests that the event managed to generate a notable degree of exposure to and interaction across multiple queer communities. Thus, events like Queeriosity have the potential to significantly benefit queer youth identity development and social connectedness.

\section{Contributor}

Dr Jodie Taylor is a Research Fellow at the Queensland Conservatorium Research Centre, Griffith University. She is the author of Playing it Queer: Popular Music, Identity and Queer World-making (Peter Lang Press 2012) and co-editor of two forthcoming collections: The Festivalisation of Culture (Ashgate 2012) and Redefining Mainstream Popular Music (Routledge 2012). Additionally, Jodie has authored numerous scholarly journal articles and book chapters on popular music and sexuality, queer cultural practices and ethnographic methods. 


\section{Endnotes}

\footnotetext{
${ }^{i}$ Due to interruptions in their weekly routines - school activities, university, casual work, personal or health issuesyoung people's attendance at festival planning meetings would vary. In some instances participation was high with around 15 attendants, and at other times it was low with only four or five people turning up to meetings. There was however, a core group of seven young people who demonstrated a strong commitment to the event during the entire process.

ii The $11 \%$ of respondents that identified as heterosexual is an interesting statistic. Since the festival welcomed queer, questioning and curious young people it could be that some of these young people were gender and/or sexually curious or even queer, but chose to maintain a heterosexual identity (e.g. see Thomas 2000 for various discussions of queer heterosexualities). Or, since it cannot be automatically assumed that straight sexualities are easy achievements, it could point to complex issues surrounding the construction of youth sexuality in broader terms. Unfortunately, it was beyond the scope of the article to explore this further.

iii A number of scholars have offered useful critiques of the increasing corporatisation and commodification of pride festivals as mega tourist events (e.g. Bell and Binnie 2004) and others still have argued that a coherent assertion of a collective lesbian and gay identity under the banner of pride is exclusionary and outmoded (e.g. Halperin and Traub 2009). While I tend to agree with these literatures, I would argue that given Queeriosity was completely free (entry, food and drink was free and there was nothing available for sale on the day) and it was not predicated on discourses of pride, it potentially avoided many of these trappings. However, further critical analysis would be required to qualify this.

${ }^{\text {iv }}$ Brisbane Queer Film Festival contains films that are unclassified and resultantly the entire festival is rated R, therefore attendance is legally restricted to people 18+years.

'A broad range of 'identity journeys' were discussed. But for the purposes of illustration some of these were: experiences of transitioning from male to female; transitioning from female to male; experiences of trying to 'pass' as straight; identifying as queer or genderqueer and what that means; experiences of bi-phobia; coming out in your teens, 20s, 30s and 40s; coming out in a family/community where religious beliefs conflict with sexual feelings.
}

\section{Reference List}

Altman, D., 1972. Homosexual oppression and liberation. Sydney: Angus \& Robertson.

Bell, D. and Binnie, J., 2004. Authenticating queer space: Citizenship, urbanism and governance. Urban Studies, 41(9), 1807-1820.

Bennett, A., 2000. Popular music and youth culture: Music, identity and place. Houndmills: Macmillan Press.

Butler, J., 1993. Bodies that matter: On the discursive limits of sex. New York: Routledge.

Driver, S., 2008. Introduction. In S. Driver, ed. Queer youth subcultures. Albany: State University of New York Press, 1-18.

Foucault, M., 1979. The history of sexuality: Vol. 1. An introduction. (R. Hurley, Trans.). London: Allen Lane.

Grov, C., Bimbi, D.S., Nanín, J.E. and Parsons, J.T., 2006. Race, ethnicity, gender, and generational factors associated with the coming-out process among gay, lesbian, and bisexual individuals. The Journal of Sex Research, 43(2), 115-121.

Halperin, D. and Traub, V., 2009. Beyond gay pride. In D. Halperin and V. Traub, eds, Gay Shame. Chicago: University of Chicago Press, 3-40.

Halverson, E. R., 2005. InsideOut: Facilitating gay youth identity development through a performance-based youth organization. Identity, 5(1), 67-90.

Hillier, L., Turner, A. and Mitchell, A., 2005. Writing themselves in again: Six years on. The second national report on the sexuality, health and well-being of same-sex attracted young people in Australia. Melbourne: La Trobe University.

Hodkinson, P., 2005. 'Insider research' in the study of youth cultures. Journal of Youth Studies, $8(2), 131-149$.

Jackson, S. and Scott, S., 2004. Sexual antinomies in late modernity. Sexualities, 7(2), 233-248.

Kates, S. and Belk, R., 2001. The meanings of lesbian and gay pride day: Resistance through consumption and resistance to consumption. Journal of Contemporary Ethnography, 30(4), $392-429$.

Linné, R., 2003. Alternative textualities: Media culture and the proto-queer. International Journal of Qualitative Studies in Education, 16(5), 669-689. 
Madden, R., 2010. Being ethnographic: A guide to the theory and practice of ethnography. London: Sage.

Martino, W. and Pallotta-Chiarolli, M., 2005. Being normal is the only way to be: Adolescent boys and girls perspectives on gender and school. Sydney: UNSW Press.

Pallotta-Chiarollli, M., 2010. Border sexualities, border families in schools. New York: Rowman and Littlefield.

Riggs, D.W., 2006. Priscilla, (white) queen of the desert: Queer rights/race privilege. New York: Peter Lang

Robson, C., 2000. Real world research. Oxford: Blackwell.

Shelton, J., 2008. Redefining realities through self-representational performance. In S. Driver, ed. Queer youth subcultures. Albany: State University of New York Press, 69-86.

Skeggs, B., 2004. Class, self, culture. London: Routledge.

Talburt, S., Rofes, E. and Rasmussen, M.L., 2004. Introduction. In M. L Rasmussen, E. Rofes and S. Talburt, eds. Youth and sexualities: Pleasure, subversion, and insubordination in and out of schools. New York: Palgrave, 1-13.

Taylor, J. 2011. The intimate insider: Negotiating the ethics of friendship when doing insider research. Qualitative Research, 11(1), 3-22.

Thomas, C., ed. 2000. Straight with a twist: Queer theory and the subject of heterosexuality. Champaign, IL: University of Illinois Press.

Trenwith, C., 2010. Queensland's 'alarming' gay phobia. Brisbane Times, 15 November. Available from: http://www.brisbanetimes.com.au/queensland/queenslands-alarming-gay-phobia20101115-17txg.html [Accessed 20 January 2011].

Waitt, G. and Markwell, K., 2006. Gay tourism: Culture and context. Binghamton, NY: The Haworth Hospitality Press. 